Research report

\title{
Changes in striatal dopamine release and locomotor activity following acute withdrawal from chronic nicotine are mediated by CRF1, but not CRF2, receptors
}

\author{
András Buzás, Péter Bokor, Beáta Balangó, Dávid Pintér, Miklós Palotai, Balázs Simon, \\ Krisztina Csabafi, Gyula Telegdy, Gyula Szabó, Zsolt Bagosi*
}

Department of Pathophysiology, Faculty of Medicine, University of Szeged, Hungary

\section{H I G H L I G H T S}

- Male Wistar were exposed to repeated ip injection with nicotine for 7 days.

- On the 8th and the 9th day rats were injected icv with antalarmin or astressin $2 \mathrm{~B}$.

- Horizontal and vertical locomotor activities changed on the 8th and the 9th day.

- Dorsal and ventral striatal dopamine releases changed on the 8th and the 9th day.

- All the changes observed were attenuated by antalarmin, but not astressin ${ }_{2 \mathrm{~B}}$.

\section{A R T I C L E I N F O}

\section{Keywords:}

Striatal dopamine release

Locomotor activity

Rats

Nicotine

CRF receptor

\begin{abstract}
A B S T R A C T
The aim of the present study was to investigate the participation of corticotropin-releasing factor (CRF) receptors (CRF1 and CRF2) in the alterations of the dorsal and ventral striatal dopamine release and the vertical and horizontal locomotor activity observed in rats following chronic nicotine treatment and consequent acute withdrawal. In this purpose, male Wistar rats were exposed to repeated intraperitoneal (ip) injection with nicotine or saline solution for 7 days. On the 8 th day or the 9 th day the rats were injected intracerebroventricularly (icv) with selective CRF1 antagonist antalarmin or selective CRF2 antagonist astressin ${ }_{2 \mathrm{~B}}$ or saline solution. Thirty minutes after the icv injection the changes of the horizontal and vertical locomotor activity were recorded in an in vivo conducta system. Immediately after the behavioral recordings the changes of the dorsal and ventral striatal dopamine release were determined in an in vitro superfusion system. On the 8th day, the horizontal and vertical locomotor activities and the dorsal and ventral striatal dopamine releases increased significantly in nicotine-treated rats, compared to the saline-treated ones. On the 9th day, the horizontal locomotor activity and the dorsal striatal dopamine release increased significantly, whereas the vertical locomotor activity and the ventral striatal dopamine release decreased significantly in nicotine-treated rats, compared to the saline-treated ones. All the changes observed were attenuated significantly by antalarmin, but not astressin ${ }_{2 \mathrm{~B}}$. The present study demonstrates that the changes of striatal dopamine release and locomotor activity observed following chronic nicotine treatment and consequent acute withdrawal are mediated by CRF1, but not CRF2, receptor.
\end{abstract}

\section{Introduction}

Corticotropin-releasing factor (CRF) is a hypothalamic neurohormone, but also an extrahypothalamic neurotransmitter, that regulates the neuroendocrine, autonomic and behavioral stress reponses (Bale et al., 2002; Bale and Vale, 2004; Vale et al., 1981). The actions of $\mathrm{CRF}$ are mediated by two distinct $\mathrm{G}$ protein-coupled receptors, CRF receptor type 1 (CRF1) and CRF receptor type 2 (CRF2) (Chang et al., 1993; Lovenberg et al., 1995). CRF1 is expressed abundantly in the central nervous system (CNS), including the cerebral cortex, cerebellum and striatum (Van Pett et al., 2000). CRF2 is expressed predominantly in the periphery, and limited centrally to subcortical regions, such as the hypothalamus, hippocampus and amygdala (Van Pett et al., 2000). Originally, it was suggested that CRF1 and CRF2 mediate antagonistic

\footnotetext{
* Corresponding author at: Department of Pathophysiology, University of Szeged, Semmelweis str. 1, 6725 Szeged, Hungary.

E-mail address: bagosi.zsolt@med.u-szeged.hu (Z. Bagosi).
} 
effects in the CNS, since stimulation of CRF1 provoked activation of the HPA axis, anxiety and depression, and increase of locomotor activity (at least in a familial environment), whereas stimulation of CRF2 evoked anxiolytic and antidepressant effects, and decrease of locomotor activity (Bale et al., 2002; Bale and Vale, 2004; Vale et al., 1981). Recently, it was demonstrated that the role of CRF receptors in the stress responses is not a matter of simple dualism, but it depends upon the brain regions and neuron populations being activated (Henckens et al., 2016; Janssen and Kozicz, 2013).

Nicotine is the main psychoactive component of tobacco that causes addiction. Besides the regulation of the stress responses, CRF has been implicated in nicotine addiction based on several lines of evidence (Bruijnzeel and Gold, 2005; Sarnyai et al., 2001). First, acute administration of nicotine, like any other stressor, evokes a dose-dependent activation of the hypothalamic-pituitary-adrenal (HPA) axis that is initiated by hypothalamic CRF (Bruijnzeel and Gold, 2005; Sarnyai et al., 2001). Second, nicotine withdrawal syndrome resembles the behavioral stress response that is mediated by extrahypothalamic CRF (Bruijnzeel and Gold, 2005; Sarnyai et al., 2001). Third, exposure to stressors is one of the leading causes of nicotine relapse (Bruijnzeel and Gold, 2005; Sarnyai et al., 2001). Finally, both CRF receptors participate to the acute, chronic and withdrawal actions of nicotine (Bruijnzeel et al., 2009; Bruijnzeel, 2012; George et al., 2007; Kamdi et al., 2009; Marcinkiewcz et al., 2009). The actions of nicotine are mediated by nicotinic acetylcholine receptors (nAchRs) that are considered ligand-gated ion channels composed of pentameric combinations of $\alpha$ and $\beta$ subunits, since normally they respond to acetycholine and allow natrium or calcium ions to enter the cells (Benowitz, 2010). Based on their primary sites of expression, nAchRs are classified into two subtypes: muscle-type nicotinic receptors found in neuromuscular junctions and neuronal-type nicotinic receptors found on neuronal bodies and nerve terminals (Benowitz, 2010). The most abundant neuronal nAchRs are $\alpha 4 \beta 2, \alpha 3 \beta 4$ and $\alpha 7$ located both pre- and postsynaptically where they can influence the release of other neurotransmitters, such as dopamine, glutamate and GABA (Benowitz, 2010).

Some of the psychoactive actions of nicotine are mediated by the nigrostriatal and mesolimbic pathways (Di Chiara, 2000; Di Chiara et al., 2004). The nigrostriatal pathway originates in the dopaminergic neurons located in the substantia nigra and terminates in the putamen and nucleus caudatus which together constitute the dorsal striatum (Di Chiara, 2000; Di Chiara et al., 2004). The mesolimbic pathway arises from the dopaminergic neurons situated in the ventral tegmental area and projects to the nucleus accumbens that represents the ventral striatum (Di Chiara, 2000; Di Chiara et al., 2004). Classically, the nigrostriatal pathway controls motor behavior, posture and learning of motor programs and habits, whereas the mesolimbic pathway contributes to motor behavior by mediation of reward, emotion and motivation (Everitt and Robbins, 2013). Nevertheless, manipulations of dopamine release in the dorsal and ventral striatum affect motor behavior in distinct, but parallel ways, which depend upon the nature of the cortical and limbic input to these brain structures (Everitt and Robbins, 2013). Acute administration of nicotine increases the release of striatal dopamine that is associated with a sensation of reward and locomotor hyperactivity in rats (Fung and Lau, 1986, 1989). Chronic administration of nicotine also increases the striatal dopamine release, although its impact on the locomotor activity depends upon the dose and schedule of administration (Fung and Lau, 1991, 1992). Usually, continuous infusion of nicotine several times a day may induce tolerance, while repetitive injection once a day may produce sensitization to the effects of nicotine (Di Chiara, 2000; Di Chiara et al., 2004). Nicotine also augments glutamate release, which stimulates the release of dopamine, and GABA release, which inhibits the release of dopamine. With long-term exposure to nicotine, some nAchRs become desensitized, but some do not (Benowitz, 2008, 2010). As a result, GABAergic inhibitory tone diminishes, while glutamatergic excitation continues, thereby increasing excitation of dopaminergic neurons and enhancing responsiveness to nicotine (Benowitz, 2008, 2010). Acute withdrawal following chronic administration of nicotine causes a nicotine withdrawal syndrome that starts promptly within few hours and peaks around $24 \mathrm{~h}$ following cessation of chronic nicotine administration (Fung et al., 1996). The nicotine withdrawal syndrome in rats consists of a somatic component, characterized by locomotor hypoactivity, increased appetite and weight gain and an affective component, represented by anxiety, depression and reward deficit (Kenny and Markou, 2001). Some of the affective symptoms, such as anxiety and depression, may persist during chronic nicotine withdrawal (Kenny and Markou, 2001). The basis of nicotine addiction is a combination of positive reinforcement, given by the rewarding, positive effects of nicotine, and negative reinforcement, maintained by the avoidance of the aversive, negative effects of nicotine withdrawal (Benowitz, 2010). The changes of the dorsal and ventral striatal dopamine release can be partly or entirely implicated in both forms of reinforcement, and reflected in the changes of the horizontal and vertical locomotor activity (Di Chiara, 2000; Di Chiara et al., 2004). Therefore, these behavioral and neurochemical parameters can be considered important measures of nicotine addiction (Fung et al., 1996).

The aim of the present study was to investigate the participation of CRF1 and CRF2 in the alterations of the dorsal and ventral striatal dopamine release and the vertical and horizontal locomotor activity observed in rats following chronic nicotine treatment and consequent acute withdrawal. In this purpose, male Wistar rats were exposed to repeated intraperitoneal (ip) injection with $1.4 \mathrm{mg} / \mathrm{kg}$ nicotine or saline solution for 7 days, two times/day (at 8:00 and at 20:00). Thus, $12 \mathrm{~h}$ passed between the nicotine treatments. This dose and schedule of administration should produce plasma nicotine levels in rats similar to plasma nicotine levels found in an individual who smokes 1-2 packs of cigarettes a day (Benowitz, 2008). In order to assess the behavioral and neurochemical changes induced by chronic nicotine treatment and acute nicotine withdrawal the rats were investigated on the morning of the 8th day ( $12 \mathrm{~h}$ after the last ip administration) and the 9th day (24 $\mathrm{h}$ after the last ip administration), respectively. Furthermore, the rats were injected intracerebroventricularly (icv) with selective CRF1 receptor antagonist antalarmin or selective CRF2 receptor antagonist astressin $_{2 B}$ or saline solution on the 8th day or the 9th day. Thirty minutes after the icv injection the changes of the horizontal and vertical locomotor activity were recorded in an in vivo conducta system. Immediately after the behavioral recordings the changes of the dorsal and ventral striatal dopamine release were determined in an in vitro superfusion system.

\section{Results}

On the 8th day, the horizontal (Fig. 1) and vertical locomotor activity (Fig. 2) and the dorsal (Fig. 3) and ventral striatal dopamine release (Fig. 4) increased significantly in nicotine-treated rats, compared with the saline-treated rats. Tukey post-hoc test revealed the following $p$ values: $p<0.0001$ for horizontal locomotor activity, $p=0.0043$ for vertical locomotor activity, $\mathrm{p}<0.0001$ for dorsal striatal dopamine release, and $\mathrm{p}<0.0001$ for ventral striatal dopamine release. All the changes observed on the 8th day were reduced significantly by icv treatment with antalarmin, but not astressin ${ }_{2 \mathrm{~B}}$ (Figs. 1-4). Tukey posthoc test indicated the following $\mathrm{p}$ values: $\mathrm{p}=0.0304$ for horizontal locomotor activity, $\mathrm{p}=0.0002$ for vertical locomotor activity, $\mathrm{p}<0.0001$ for dorsal striatal dopamine release, and $\mathrm{p}<0.0001$ for ventral striatal dopamine release.

On the 9th day, the horizontal locomotor activity (Fig. 1) and the dorsal striatal dopamine release (Fig. 3) were increased significantly, while the vertical locomotor activity (Fig. 2) and the ventral striatal dopamine release (Fig. 4) were decreased significantly in the nicotinetreated rats, compared with the saline-treated rats. Tukey post-hoc test revealed the following $\mathrm{p}$ values: $\mathrm{p}<0.0001$ for horizontal locomotor activity, $\mathrm{p}=0.0033$ for vertical locomotor activity, $\mathrm{p}<0.0009$ for 


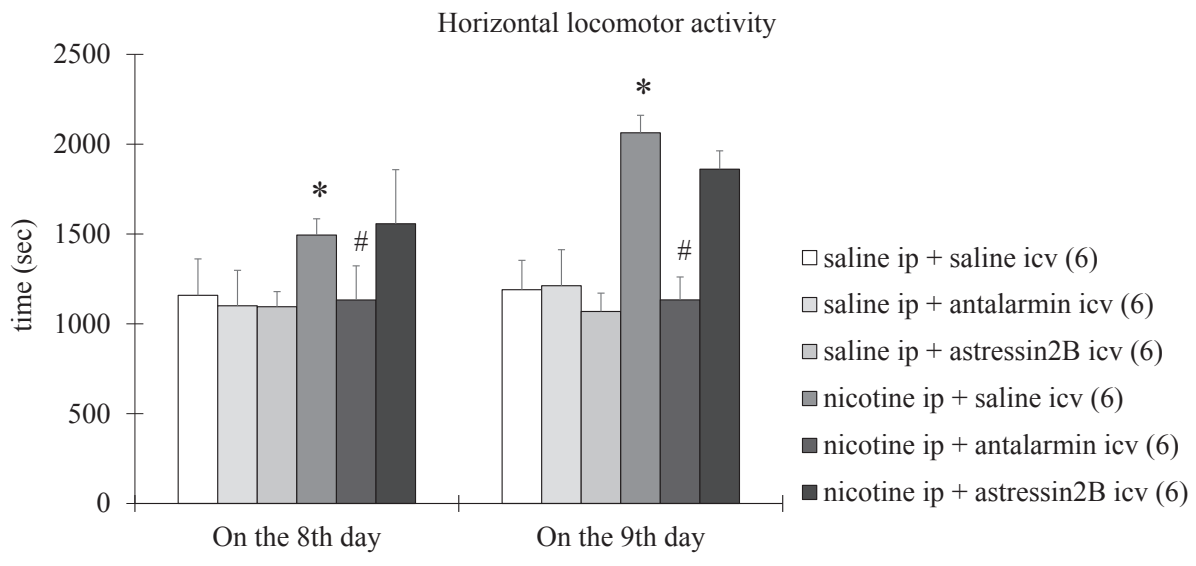

Fig. 1. The horizontal locomotor activity in rats exposed to 7 days of nicotine treatment and 1 day of withdrawal. Behavioral parameters were determined on the 8th and the 9th day. Values are presented as means \pm SEM. Statistically significant difference was accepted for $\mathrm{p}<0.05$ and indicated with * for nicotine ip + saline icv vs. saline ip + saline icv and with \# for nicotine ip + antalarmin icv vs. nicotine ip + saline icv. dorsal striatal dopamine release, and $\mathrm{p}<0.0002$ for ventral striatal dopamine release. All the changes assessed on the 9th day were reversed completely by icv treatment with antalarmin, but not astressin $\operatorname{sB}_{2 \mathrm{~B}}$ (Figs. 1-4). Tukey post-hoc test indicated the following $\mathrm{p}$ values: $\mathrm{p}<0.0001$ for horizontal locomotor activity, $\mathrm{p}=0.0321$ for vertical locomotor activity, $\mathrm{p}=0.0022$ for dorsal striatal dopamine release, and $\mathrm{p}<0.0001$ for ventral striatal dopamine release. A summary of the effects of the antagonist treatment, the nicotine treatment and the interaction between them is presented in Tables 1-4.

\section{Discussion}

In rats exposed to 7 days of nicotine treatment $(12 \mathrm{~h}$ after the last nicotine administration) we observed increases in horizontal and vertical locomotor activity along with increases in the dorsal and ventral striatal dopamine release. This finding is in line with previous studies which reported locomotor hyperactivity on the 4th and the 10th day of a chronic nicotine exposure (Fung and Lau, 1991, 1992). The authors of these studies suggested that nicotine-treated rats develop locomotor hyperactivity in response to nicotine initially due to increases of both the density of dopamine receptors (D1 and D2) and dopamine concentration, and lately due to dopamine receptor supersensitivity in the striatum (Fung and Lau, 1988). The interpretation of the behavioral changes observed following chronic nicotine treatment is somewhat complicated by the observation that the impact of chronic nicotine exposure on locomotion depend upon sex, age, and housing conditions (Faraday et al., 1999b, 2001, 2003a,b, 2005). Female animals are less sensitive to the acute and chronic effects of nicotine, but more sensitive to the impact of acute nicotine withdrawal, including the neuroendocrine and behavioral stress responses, when compared to males (Bangasser and Wiersielis, 2018; Becker, 2016; Faraday et al., 1999a, 2003b, 2005). As regards the locomotor actions of nicotine in male and female Long-Evans and Sprague-Dawley rats, the horizontal activity was more enhanced in Long-Evans females, and the vertical activity was unaltered in Sprague-Dawley males (Faraday et al., 2003b). Also, younger animals exhibit increased sensitivity to the positive, rewarding effects of nicotine and reduced sensitivity to the negative, aversive effects of nicotine withdrawal which may contribute to the higher risk to develop nicotine addiction in adolescents, when compared to adults (Faraday et al., 2003a; Portugal et al., 2012). As regards the locomotor actions of nicotine, during chronic nicotine administration adolescent males exhibited a greater locomotor activity, when compared to adult males or adolescent females (Faraday et al., 2001). During nicotine cessation, nicotine-treated adolescent males continued to exhibit greater locomotor activity than saline-treated animals (Faraday et al., 2001). Another possible factor influencing the results is the housing condition (Faraday et al., 1999b). In saline-treated rats, group housing decreased the horizontal and vertical activity and the center time, a measure of anxiety with effects ocurring sooner in females (Faraday et al., 1999b). For males, nicotine altered both the horizontal and vertical activity, increasing these variables for group-housed males, but decreasing them for individually housed males (Faraday et al., 1999b). For females, nicotine altered only the center time, reducing this measure of anxiety for group-housed females (Faraday et al., 1999b). During nicotine cessation, housing effects appeared more robustly in males and continued in females (Faraday et al., 1999b). Therefore, investigation of additional factors, such as sex, age and housing conditions is desirable, but would require more complex experimental design and statistical analysis.

In rats exposed to 1 day of nicotine withdrawal $(24 \mathrm{~h}$ after the last nicotine administration) we expected a decrease of general locomotor activity and a decrease of global striatal dopamine release, which were assessed in a previous study following 14 days of nicotine exposure and $24 \mathrm{~h}$ of nicotine withdrawal (Fung et al., 1996). Interestingly, in the

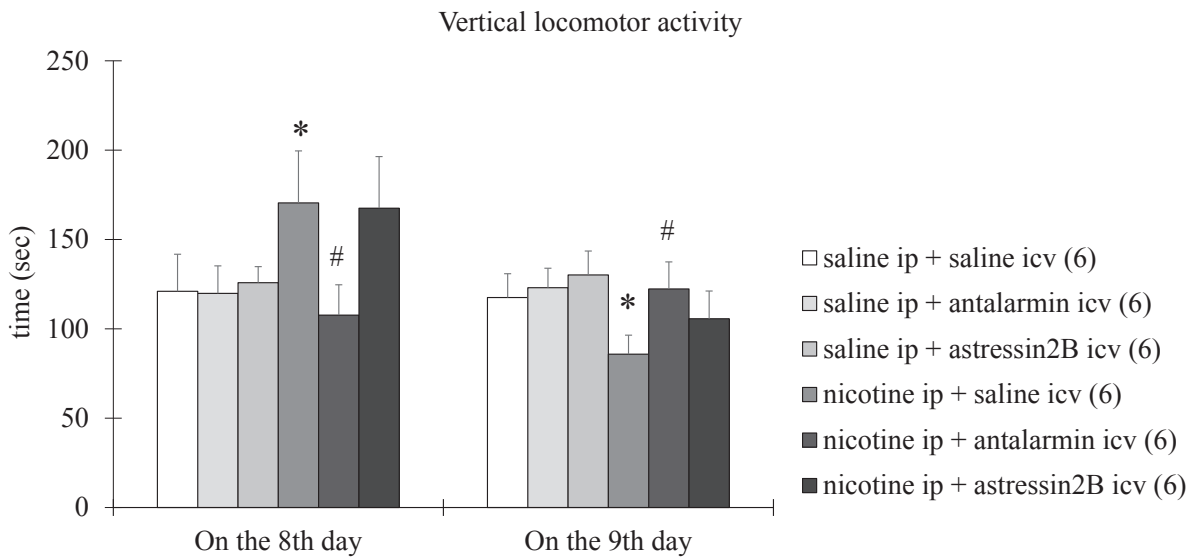

Fig. 2. The vertical locomotor activity in rats exposed to 7 days of nicotine treatment and 1 day of withdrawal. Behavioral parameters were determined on the 8th and the 9th day. Values are presented as means \pm SEM. Statistically significant difference was accepted for $\mathrm{p}<0.05$ and indicated with * for nicotine ip + saline icv vs. saline ip + saline icv and with \# for nicotine ip + antalarmin icv vs. nicotine ip + saline icv. 


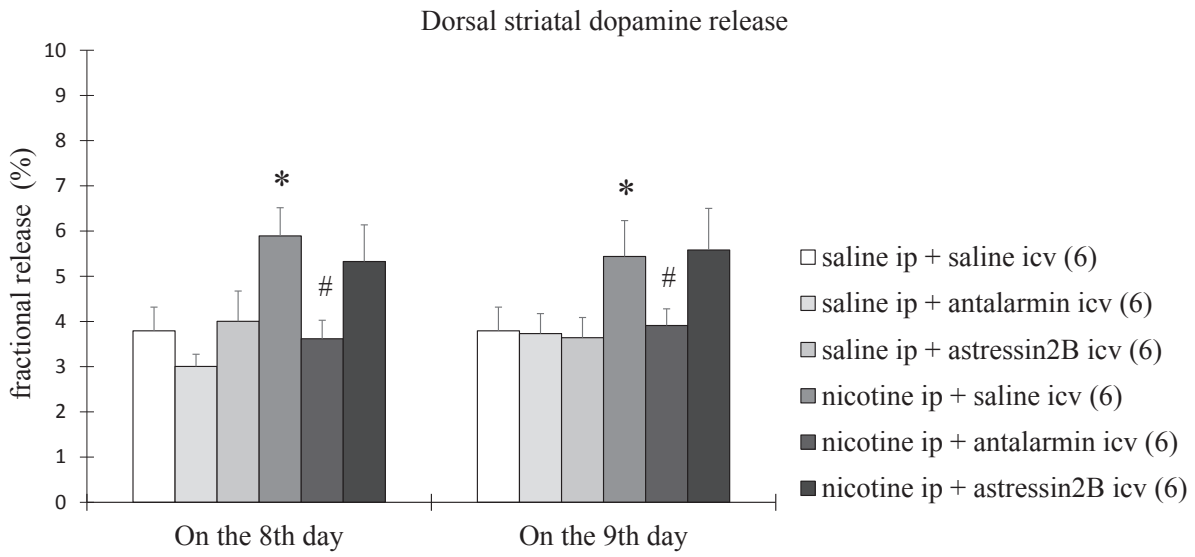

Fig. 3. The dorsal striatal dopamine release in rats exposed to 7 days of nicotine treatment and 1 day of withdrawal. Biochemical parameters were determined on the 8th and the 9th day. Values are presented as means \pm SEM. Statistically significant difference was accepted for $\mathrm{p}<0.05$ and indicated with * for nicotine ip + saline icv vs. saline ip + saline icv and with \# for nicotine ip + antalarmin icv vs. nicotine ip + saline icv. present study only the vertical locomotor activity and the ventral striatal dopamine release were decreased, while the horizontal locomotor activity and the dorsal striatal dopamine release remained increased following acute nicotine withdrawal. The explanation of this finding might be offered by the authors of this previous study, who showed a reduction of the maximum number of $\mathrm{D} 2$ receptor sites in the nucleus accumbens, but found no alteration of the density and binding affinity of dopamine receptors (D1 and D2) in the putamen and nucleus caudatus (Fung and Lau, 1988). Additionally, the dose and the schedule of the nicotine exposure may also contribute to the difference between the previous and present results. Thus, while tolerance is more likely to be induced by continuous infusion of nicotine (performed in the previous study), sensitization is frequently induced by intermittent injection of nicotine (performed in the present study) (Di Chiara, 2000; Di Chiara et al., 2004). Nonetheless, continuous exposure to nicotine at doses that result in tolerance to the nicotine-induced sensitization, induces itself a sensitization that is demasked as the tolerance wears off. Hereby tolerance and sensitization must be regarded as two distinct adaptive changes that usually require different conditions, but may also occur following the same dose and schedule of chronic nicotine exposure (Di Chiara, 2000; Di Chiara et al., 2004). Consequently, during acute nicotine withdrawal these competing phenomena could be manifested differently between the two subdivisions of the striatum and accordingly, the two aspects of locomotor activity (Di Chiara, 2000; Di Chiara et al., 2004). The discrepancies between the behavioral and neurochemical parameters observed following acute nicotine withdrawal is underlined by the differential nicotinic regulation of the nigrostriatal and mesolimbic dopaminergic pathways (Janhunen et al., 2005; Janhunen and Ahtee, 2007). On one hand, there are clear differences in the distribution and characteristics of various nAchR subtypes between the dorsal and ventral striatum (Exley et al., 2012, 2013;
Janhunen et al., 2005; Janhunen and Ahtee, 2007). Acute nicotine exposure increases directly the striatal dopamine neurotransmission via presynaptic nAchRs that are $\alpha 6 \beta 2$ and/or $\alpha 4 \beta 2$ subunit-containing, depending on the brain region (Janhunen et al., 2005; Janhunen and Ahtee, 2007). The nAchR subtypes that regulate dopaminergic neurotransmission depend critically upon $\alpha 5$ subunits (non- $\alpha 6$ nAchRs) in the dorsal striatum and upon $\alpha 6$ subunits ( $\alpha 6 \mathrm{nAchRs)}$ in the ventral striatum (Exley et al., 2012). Chronic nicotine exposure produces no change in the control of dopamine release by $\alpha 6$ relative to non- $\alpha 6$ nAchRs in the putamen and nucleus caudatus, but it induces a downregulation of the $\alpha 6$ nAchRs and an upregulation of non- $\alpha 6$ nAchRs in the nucleus accumbens (Exley et al., 2013). In addition, nicotine modulates the release of dopamine indirectly, through the release of glutamate and GABA following activation of post-synaptic $\alpha 7$ containing nAchRs (Exley et al., 2012, 2013; Janhunen et al., 2005; Janhunen and Ahtee, 2007). On the other hand, there are also differences in the regulation of dopamine release by different nicotinic agonists (Exley et al., 2012, 2013; Janhunen et al., 2005; Janhunen and Ahtee, 2007). For example, nicotine stimulates especially the mesolimbic dopaminergic pathway, in contrast, epibatidine, the most potent nAchR agonist known to date, stimulates preferentially the nigrostriatal pathway (Janhunen et al., 2005; Janhunen and Ahtee, 2007). The differing dose-response curves of the two nicotinic agonists regarding the dorsal and ventral striatal dopamine release suggest different abilities for downregulation and desensitization of the nAchRs found in these brain regions (Janhunen et al., 2005; Janhunen and Ahtee, 2007). This imbalance in the distribution and the function of nAchRs between the dorsal and ventral striatum might explain the dopamine dysregulation assessed during acute nicotine withdrawal.

Taken together, our results demonstrate that the changes of striatal dopamine release and locomotor activity observed following chronic

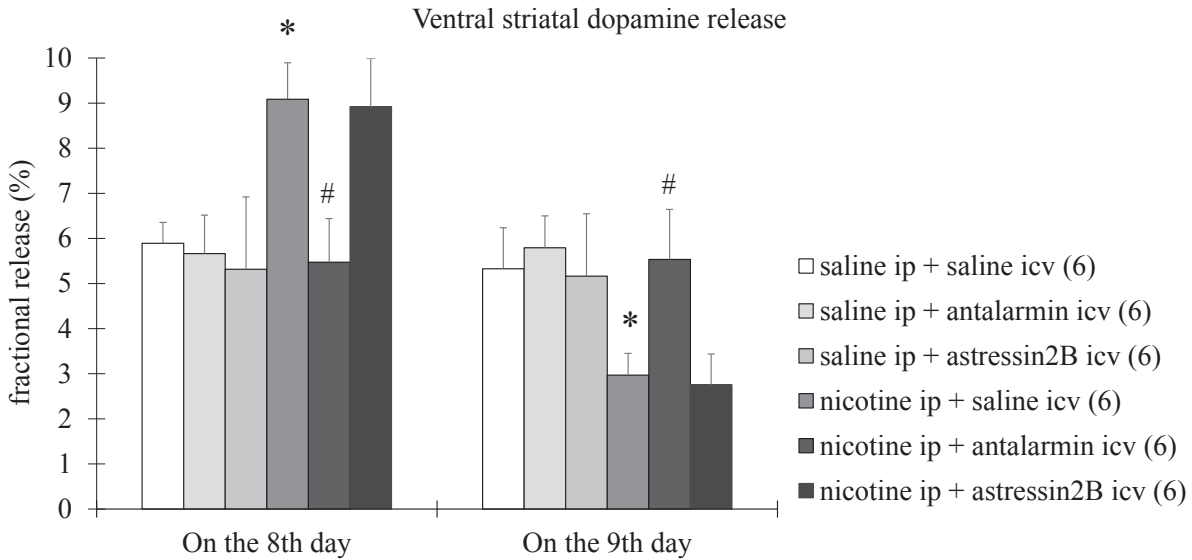

Fig. 4. The ventral striatal dopamine release in rats exposed to 7 days of nicotine treatment and 1 day of withdrawal. Biochemical parameters were determined on the 8th and the 9th day. Values are presented as means \pm SEM. Statistically significant difference was accepted for $\mathrm{p}<0.05$ and indicated with * for nicotine ip + saline icv vs. saline ip + saline icv and with \# for nicotine ip + antalarmin icv vs. nicotine ip + saline icv. 
Table 1

Statistical data for dorsal striatal dopamine release on the 8th and the 9th day.

\begin{tabular}{|c|c|c|c|c|c|}
\hline Source of variation & Degrees of freedom & Sum of squares & Mean square & F value & $\mathrm{p}$ value \\
\hline \multicolumn{6}{|c|}{ Dorsal striatal dopamine release on the 8th day } \\
\hline Antagonist treatment & 2.0 & 16.27 & 8.133 & $\mathrm{~F}(2,30)=24.28$ & $\mathrm{p}<0.0001$ \\
\hline Nicotine treatment & 1.0 & 15.61 & 15.61 & $F(1,30)=46.58$ & $\mathrm{p}<0.0001$ \\
\hline Interaction & 2.0 & 2.950 & 1.475 & $\mathrm{~F}(2,30)=4.40$ & $\mathrm{p}=0.0211$ \\
\hline \multicolumn{6}{|c|}{ Dorsal striatal dopamine release on the 9th day } \\
\hline Antagonist treatment & 2.0 & 5.022 & 2.511 & $\mathrm{~F}(2,30)=6.58$ & $\mathrm{p}=0.043$ \\
\hline Nicotine treatment & 1.0 & 14.15 & 14.15 & $\mathrm{~F}(1,30)=37.12$ & $\mathrm{p}<0.0001$ \\
\hline Interaction & 2.0 & 5.336 & 2.668 & $\mathrm{~F}(2,30)=7.00$ & $\mathrm{p}=0.0032$ \\
\hline
\end{tabular}

Table 2

Statistical data for ventral striatal dopamine release on the 8th and the 9th day.

\begin{tabular}{|c|c|c|c|c|c|}
\hline Source of variation & Degrees of freedom & Sum of squares & Mean square & F value & $\mathrm{p}$ value \\
\hline \multicolumn{6}{|c|}{ Ventral striatal dopamine release on the 8th day } \\
\hline Antagonist treatment & 2.0 & 24.91 & 12.46 & $\mathrm{~F}(2,30)=16.77$ & $\mathrm{p}<0.0001$ \\
\hline Nicotine treatment & 1.0 & 43.64 & 43.64 & $F(1,30)=58.75$ & $\mathrm{p}<0.0001$ \\
\hline Interaction & 2.0 & 26.1 & 13.00 & $\mathrm{~F}(2,30)=17.51$ & $\mathrm{p}<0.0001$ \\
\hline \multicolumn{6}{|c|}{ Ventral striatal dopamine release on the 9th day } \\
\hline Antagonist treatment & 2.0 & 20.93 & 10.46 & $\mathrm{~F}(2,30)=17.13$ & $\mathrm{p}<0.0001$ \\
\hline Nicotine treatment & 1.0 & 25.26 & 25.26 & $\mathrm{~F}(1,30)=41.34$ & $\mathrm{p}<0.0001$ \\
\hline Interaction & 2.0 & 9.025 & 4.513 & $F(2,30)=7.39$ & $\mathrm{p}=0.0025$ \\
\hline
\end{tabular}

Table 3

Statistical data for horizontal locomotor activity on the 8th and the 9th day.

\begin{tabular}{|c|c|c|c|c|c|}
\hline Source of variation & Degrees of freedom & Sum of squares & Mean square & $\mathrm{F}$ value & $\mathrm{p}$ value \\
\hline \multicolumn{6}{|c|}{ Horizontal locomotor activity on the 8 th day } \\
\hline Antagonist treatment & 2.0 & 351,737 & 175,869 & $\mathrm{~F}(2,30)=4.75$ & $\mathrm{p}=0.0161$ \\
\hline Nicotine treatment & 1.0 & 689,453 & 689,453 & $\mathrm{~F}(1,30)=18.62$ & $\mathrm{p}=0.0002$ \\
\hline Interaction & 2.0 & 292,703 & 146,351 & $\mathrm{~F}(2,30)=3.95$ & $\mathrm{p}=0.0300$ \\
\hline \multicolumn{6}{|c|}{ Horizontal locomotor activity on the 9th day } \\
\hline Antagonist treatment & 2.0 & $1.270 \mathrm{e}$ & 635,248 & $\mathrm{~F}(2,30)=33.49$ & $\mathrm{p}<0.0001$ \\
\hline Nicotine treatment & 1.0 & $2.519 \mathrm{e}$ & $2.519 \mathrm{e}$ & $\mathrm{F}(1,30)=132.81$ & $\mathrm{p}<0.0001$ \\
\hline Interaction & 2.0 & $1.671 \mathrm{e}$ & 835,490 & $\mathrm{~F}(2,30)=44.05$ & $\mathrm{p}<0.0001$ \\
\hline
\end{tabular}

Table 4

Statistical data for vertical locomotor activity on the 8th and the 9th day.

\begin{tabular}{|c|c|c|c|c|c|}
\hline $\begin{array}{l}\text { Source of } \\
\text { variation }\end{array}$ & $\begin{array}{l}\text { Degrees of } \\
\text { freedom }\end{array}$ & $\begin{array}{l}\text { Sum of } \\
\text { squares }\end{array}$ & $\begin{array}{l}\text { Mean } \\
\text { square }\end{array}$ & F value & $\mathrm{p}$ value \\
\hline \multicolumn{6}{|c|}{ Vertical locomotor activity on the 8th day } \\
\hline $\begin{array}{l}\text { Antagonist } \\
\text { treatment }\end{array}$ & 2.0 & 8433 & 4217 & $\mathrm{~F}(2,30)=9.31$ & $\mathrm{p}=0.0007$ \\
\hline $\begin{array}{l}\text { Nicotine } \\
\text { treatment }\end{array}$ & 1.0 & 6241 & 6241 & $F(1,30)=13.78$ & $\mathrm{p}=0.0008$ \\
\hline Interaction & 2.0 & 6762 & 3381 & $\mathrm{~F}(2,30)=7.47$ & $p=0.0023$ \\
\hline \multicolumn{6}{|c|}{ Vertical locomotor activity on the 9th day } \\
\hline $\begin{array}{l}\text { Antagonist } \\
\text { treatment }\end{array}$ & 2.0 & 3627 & 1814 & $\mathrm{~F}(2,30)=10.28$ & $\mathrm{p}=0.0004$ \\
\hline $\begin{array}{l}\text { Nicotine } \\
\text { treatment }\end{array}$ & 1.0 & 3230 & 3230 & $F(1,30)=18.30$ & $\mathrm{p}=0.0002$ \\
\hline Interaction & 2.0 & 863.7 & 431.9 & $\mathrm{~F}(2,30)=2.45$ & $\mathrm{p}=0.1036$ \\
\hline
\end{tabular}

nicotine treatment and consequent acute withdrawal are mediated by CRF1, but not CRF2. Previous studies have already indicated that blocking CRF1 would prevent some of the affective symptoms (the dysphoria and the reward deficit) (Bruijnzeel et al., 2009, 2012; George et al., 2007; Marcinkiewcz et al., 2009), whereas blocking CRF2 would reverse some of the somatic symptoms (the excessive food intake and the increased body weight) of nicotine withdrawal syndrome in rats (Kamdi et al., 2009). A recent study have also indicated that administration of selective CRF2 agonists could ameliorate the anxiety- and depression-like state developed during acute nicotine withdrawal in mice (Bagosi et al., 2016). The present study completes the previous ones, suggesting that both the rewarding, positive reinforcing effects of nicotine promoted by enhanced striatal dopamine release and the aversive, negative effects of nicotine withdrawal mediated partly by deficient striatal dopamine release could be attenuated by administration of selective CRF1 antagonists. As such, antalarmin may normalize the striatal dopamine release by blocking CRF1 receptors that regulate dopamine neuron firing at the level of the substantia nigra and the ventral tegmental area (Van Pett et al., 2000). Alternatively, antalarmin may inhibit CRF1 receptors located in the dorsal and ventral striatum, but also in the amygdala and hippocampus, from where it can modulate bidirectionally the striatal dopamine release via GABAergic and glutamatergic neurotransmission (Bagosi et al., 2006, 2008, 2015; Palotai et al., 2013a,b). The present study does not exclude the possibility that the ability of the selective antagonist of CRF1, but not CRF2, to abolish the behavioral and neurochemical effects of nicotine could simply be due to the differential distribution of CRF1 and CRF2 receptors in the substantia nigra and ventral tegmental area or the dorsal and ventral striatum. Moreover, previous studies demonstrated that CRF1 is expressed abundantly in all these brain regions, whereas CRF2 is limited centrally to the hypothalamus, amydgala, and hippocampus (Van Pett et al., 2000). However, a recent study reported an increased expression of CRF2 in the dorsal striatum after the development of nicotine-induced sensitization in rats (Carboni et al., 2018). In this order of thoughts, both CRF1 and CRF2 must be considered potential targets in the therapy of nicotine addiction. 


\section{Experimental procedures}

\subsection{Animals}

Male Wistar rats weighing 150-250 g upon arrival were used $(\mathrm{N}=80)$. Although sexually maturized, the rats were considered adolescents, since they were about 6-7 weeks old when the experimental procedures (treatment, in vivo procedures, etc.) had started (Sengupta, 2013). Pre-adolescence and adolescence are developmental periods associated with increased vulnerability for nicotine addiction, and exposure to nicotine during these periods may lead to long-lasting changes in behavioral and neuronal plasticity in different brain regions, such as the cerebral cortex, hippocampus and striatum (Philpot et al., 2012; Portugal et al., 2012). In the present study only male animals were used, as previous studies suggested that the behavior of females would be influenced by too many variables, including hormonal fluctuations associated with the female reproductive cycle (Bangasser et al., 2018; Bangasser and Wiersielis, 2018; Becker and Koob, 2016; Dluzen and Anderson, 1997). However, a recent meta-analysis demonstrated that female rats were not more variable regarding behavioral, electrophysiological, neurochemical, and histological measures at any stage of the estrous cycle than male rats (Becker et al., 2016). Thus, future studies should include both male and female rats, and power analyses based on variance in male measures should be sufficient to yield accurate numbers for females as well, even when the estrous cycle is not taken into consideration. The rats were housed together and kept in their home cages at a constant temperature on a standard illumination schedule with 12-h light and 12-h dark periods (lights on from 6:00). Commercial food and tap water were available ad libitum. To minimize the effects of nonspecific stress the rats were handled daily. The rats were treated in accordance with the instructions of the Ethical Committee for the Protection of Animals in Research, University of Szeged, Hungary.

\subsection{Surgery}

The rats were implanted with a stainless steel Luer cannula $(10 \mathrm{~mm}$ long), aimed at the right lateral cerebral ventricle under anesthesia with $60 \mathrm{mg} / \mathrm{kg}$ pentobarbital sodium (Euthanasol, CEVA-Phylaxia, Hungary). The stereotaxic coordinates were $0.2 \mathrm{~mm}$ posterior and $1.7 \mathrm{~mm}$ lateral to the bregma, $3.7 \mathrm{~mm}$ deep from the dural surface, according to the stereotaxic atlas of the rat brain (Pellegrino et al., 1979). Cannulas were secured to the skull with dental cement and acrylate. The rats were allowed for 7 days to recover before experiments were started. After the experiments were concluded, $10 \mu \mathrm{l}$ of methylene blue (Reanal Ltd., Hungary) at $1 \mathrm{~g} / 100 \mathrm{ml}$ were injected into the lateral cerebral ventricle of the decapitated animals and the position of the cannula was inspected visually. The spread of methylene blue throughout the ventricular space indicated that the whole amount of the CRF antagonist got into the ventricles. Animals without the dye in the lateral cerebral ventricle ( 8 from 80 ) were excluded from the final statistical analysis. No histological preparations were performed.

\subsection{Treatments}

The rats were treated ip with $1.4 \mathrm{mg} / \mathrm{kg} / 10 \mathrm{ml}$ nicotine tartrate (Sigma-Aldrich Inc., USA) or $10 \mathrm{ml} / \mathrm{kg}$ of $0.9 \%$ saline solution (B. Braun Inc., Germany) for 7 days, two times/day (at 8:00 and at 20:00). One half of the animals were treated icv with $0.1 \mu \mathrm{g} / 2 \mu \mathrm{l}$ antalarmin (SigmaAldrich Inc., USA), a selective CRF1 antagonist, or $1 \mu \mathrm{g} / 2 \mu \mathrm{l}$ astressin $2 \mathrm{~B}$ (Sigma-Aldrich Inc., USA), a selective CRF2 antagonist, or $2 \mu \mathrm{l}$ of $0.9 \%$ saline solution (B. Braun Inc., Germany) on the 8th day (12 h after the last ip administration). The other half of the animals were treated icv on the 9th day ( $24 \mathrm{~h}$ after the last ip administration) based on the same treatment protocol. Hence, rats were divided in 6 groups: group $1-$ saline ip + saline icv; group 2 - saline ip + antalarmin icv; group 3 - saline ip $+\operatorname{astressin}_{2 \mathrm{~B}}$ icv; group 4 - nicotine ip + saline icv; group 5 nicotine ip + antalarmin icv; and group $6-$ nicotine ip $+\operatorname{astressin}_{2 \mathrm{~B}}$ icv.

\subsection{In vivo procedure}

Thirty minutes after the icv injection, the horizontal and vertical locomotor activities were recorded in an in vivo conducta system (MDE, Ltd, Germany), which is based on the principles of the open-field test and was described in our previous studies (Liptak et al., 2013; Szakacs et al., 2015). The apparatus was a square open-field black box with a side length of $60 \mathrm{~cm}$, surrounded by a $40 \mathrm{~cm}$ high wall. The floor of the box was divided in $36(6 \times 6)$ small squares. Five by five rows of photocell beams allowed a computer-based system to register the behavioral activity of each animal. A $60 \mathrm{~W}$ light was situated $1 \mathrm{~m}$ above the arena floor. Each animal was carried to the experimental room in their home cage and placed in the center of the box with which they were familiarized for $5 \mathrm{~min}$. Then the horizontal activity, representing a measure of overall activity and arousal, and the vertical activity, representing a measure of exploratory and stereotype behavior, were monitorized for $30 \mathrm{~min}$. The box was cleaned between sessions with 96\% ethyl-alcohol (Reanal Ltd., Hungary).

\subsection{In vitro procedure}

After decapitation the changes of dorsal and ventral striatal dopamine releases were determined by an in vitro superfusion system (MDE, Ltd, Germany) described in our previous studies (Bagosi et al., 2006; Palotai et al., 2013a). The striatum was isolated and dissected in a Petri dish filled with ice-cold Krebs solution (Reanal, Hungary). The stereotaxic coordinates were $4.0 \mathrm{~mm}$ anterior and $1.0 \mathrm{~mm}$ posterior to the bregma, according to the stereotaxic atlas of the rat brain (Pellegrino et al., 1979). The dorsal striatum, including the putamen and the nucleus caudatus, and the ventral striatum, including the nucleus accumbens, were decapsulated from the surrounding white matter and separated from each other. Slices of $300 \mu \mathrm{M}$ were produced with a McIlwain tissue chopper (Campden Instruments Ltd., UK). The slices were incubated for $30 \mathrm{~min}$ in $8 \mathrm{ml}$ of Krebs solution, submerged in a water bath at $37{ }^{\circ} \mathrm{C}$ and gassed through a single-use needle with a mixture of $5 \% \mathrm{CO}_{2}$ and $95 \% \mathrm{O}_{2}$. During the incubation, the slices were labelled with $15 \mu \mathrm{mol}$ of $\left[{ }^{3} \mathrm{H}\right]$ dopamine (GE Healthcare Life Sciences Inc., USA) with a specific activity of $14 \mathrm{Ci} / \mathrm{mmol}$. Two tritiated slices were transferred to each of the four cylindrical perspex chambers of the superfusion system (MDE, Co. Ltd., Germany). Gold electrodes were attached to both halves of the superfusion chambers and connected to an ST-02 electrical stimulator (MDE, Co. Ltd., Germany). A multichannel peristaltic Gilson Minipuls 2 pump (Gilson Inc., USA) was used to maintain a constant superfusion rate of $300 \mu \mathrm{l} / \mathrm{min}$. The slices were superfused for $30 \mathrm{~min}$ to allow tissue equilibrium, and the superfusates were collected in Eppendorf tubes by a multichannel fraction collector Gilson FC 203B (Gilson Inc., USA). After 2 min electrical stimulation consisting of square-wave impulses (voltage: $100 \mathrm{~V}$, pulse length: $5 \mathrm{~ms}$, frequency: $10 \mathrm{~Hz}$ ) was delivered to each of the four chambers lasting $2 \mathrm{~min}$. The sample collecting lasted $32 \mathrm{~min}$ ( $2 \mathrm{~min}$ for each sample) and the peak of the fractional release was observed at $14 \mathrm{~min}$. The remnants of slices were solubilized in $200 \mathrm{ml}$ of Krebs solution, using an ultrasonic homogenizer Branson Sonifier 250 (Labequip Ltd., Canada). The radioactivity in the fractions and the homogenized tissue samples was measured with a liquid scintillation spectrometer (Tri-carb 2100TR, Packard Inc., USA) after the addition of $3 \mathrm{ml}$ of scintillation fluid (Ultima Gold, Packard Inc., USA). The fractional release was calculated as a percentage of the radioactivity present in each collected sample compared to the total radioactivity of the correspondent tissue. 


\subsection{Statistical analysis}

Statistical analysis of the results was performed by analysis of variance (Prism 7 Statistics, GraphPad Inc., USA). The differences between groups were determined by two-way ANOVA followed by Tukey's test for pairwise comparisons when prerequisites were fulfilled. A probability level of 0.05 or less was accepted as indicating a statistically significant difference.

\section{Acknowledgements}

The present study was supported by the following grants: TÁMOP 4.2.2-A-11/1/KONV-2012-0052, KTIA_13_NAP-A-III/8 and EFOP-3.6.216-2017-00006.

\section{References}

Bagosi, Z., Jaszberenyi, M., Bujdoso, E., Telegdy, G., 2006. The effects of corticoptropinreleasing factor and the urocortins on striatal dopamine release induced by electrical stimulation-an in vitro superfusion study. Neurochem. Res. 31, 209-213.

Bagosi, Z., Jaszberenyi, M., Szabo, G., Telegdy, G., 2008. The effects of CRF and the urocortins on $[3 \mathrm{H}] \mathrm{GABA}$ release from the rat amygdala - an in vitro superfusion study. Brain Res. Bull. 75, 15-17.

Bagosi, Z., Balango, B., Pinter, D., Csabafi, K., Jaszberenyi, M., Szabo, G., Telegdy, G., 2015. The effects of CRF and urocortins on the hippocampal glutamate release. Neurochem. Int. 90, 67-71.

Bagosi, Z., Palotai, M., Simon, B., Bokor, P., Buzas, A., Balango, B., Pinter, D., Jaszberenyi, M., Csabafi, K., Szabo, G., 2016. Selective CRF2 receptor agonists ameliorate the anxiety- and depression-like state developed during chronic nicotine treatment and consequent acute withdrawal in mice. Brain Res. 1652, 21-29.

Bale, T.L., Lee, K.F., Vale, W.W., 2002. The role of corticotropin-releasing factor receptors in stress and anxiety. Integr. Comp. Biol. 42, 552-555.

Bale, T.L., Vale, W.W., 2004. CRF and CRF receptors: role in stress responsivity and other behaviors. Annu. Rev. Pharmacol. Toxicol. 44, 525-557.

Bangasser, D.A., Eck, S.R., Telenson, A.M., Salvatore, M., 2018. Sex differences in stress regulation of arousal and cognition. Physiol. Behav. 187, 42-50.

Bangasser, D.A., Wiersielis, K.R., 2018. Sex differences in stress responses: a critical role for corticotropin-releasing factor. Hormones (Athens) 17, 5-13.

Becker, J.B., 2016. Sex differences in addiction. Dialogues Clin. Neurosci. 18, 395-402.

Becker, J.B., Koob, G.F., 2016. Sex differences in animal models: focus on addiction. Pharmacol. Rev. 68, 242-263.

Becker, J.B., Prendergast, B.J., Liang, J.W., 2016. Female rats are not more variable than male rats: a meta-analysis of neuroscience studies. Biol. Sex Differ. 7, 34.

Benowitz, N.L., 2008. Clinical pharmacology of nicotine: implications for understanding, preventing, and treating tobacco addiction. Clin. Pharmacol. Ther. 83, 531-541.

Benowitz, N.L., 2010. Nicotine addiction. N. Engl. J. Med. 362, 2295-2303.

Bruijnzeel, A.W., Gold, M.S., 2005. The role of corticotropin-releasing factor-like peptides in cannabis, nicotine, and alcohol dependence. Brain Res. Brain Res. Rev. 49, 505-528.

Bruijnzeel, A.W., Prado, M., Isaac, S., 2009. Corticotropin-releasing factor-1 receptor activation mediates nicotine withdrawal-induced deficit in brain reward function and stress-induced relapse. Biol. Psychiatry 66, 110-117.

Bruijnzeel, A.W., 2012. Tobacco addiction and the dysregulation of brain stress systems. Neurosci. Biobehav. Rev. 36, 1418-1441.

Bruijnzeel, A.W., Ford, J., Rogers, J.A., Scheick, S., Ji, Y., Bishnoi, M., Alexander, J.C., 2012. Blockade of CRF1 receptors in the central nucleus of the amygdala attenuates the dysphoria associated with nicotine withdrawal in rats. Pharmacol. Biochem. Behav. 101, 62-68.

Carboni, L., Romoli, B., Bate, S.T., Romualdi, P., Zoli, M., 2018. Increased expression of CRF and CRF-receptors in dorsal striatum, hippocampus, and prefrontal cortex after the development of nicotine sensitization in rats. Drug Alcohol Depend. 189, 12-20.

Chang, C.P., Pearse 2nd, R.V., O'Connell, S., Rosenfeld, M.G., 1993. Identification of a seven transmembrane helix receptor for corticotropin-releasing factor and sauvagine in mammalian brain. Neuron 11, 1187-1195.

Di Chiara, G., 2000. Role of dopamine in the behavioural actions of nicotine related to addiction. Eur. J. Pharmacol. 393, 295-314.

Di Chiara, G., Bassareo, V., Fenu, S., De Luca, M.A., Spina, L., Cadoni, C., Acquas, E., Carboni, E., Valentini, V., Lecca, D., 2004. Dopamine and drug addiction: the nucleus accumbens shell connection. Neuropharmacology 47 (Suppl. 1), 227-241.

Dluzen, D.E., Anderson, L.I., 1997. Estrogen differentially modulates nicotine-evoked dopamine release from the striatum of male and female rats. Neurosci. Lett. 230 $140-142$.

Everitt, B.J., Robbins, T.W., 2013. From the ventral to the dorsal striatum: devolving views of their roles in drug addiction. Neurosci. Biobehav. Rev. 37, 1946-1954.

Exley, R., McIntosh, J.M., Marks, M.J., Maskos, U., Cragg, S.J., 2012. Striatal alpha5 nicotinic receptor subunit regulates dopamine transmission in dorsal striatum. J. Neurosci. 32, 2352-2356.

Exley, R., Clements, M.A., Hartung, H., McIntosh, J.M., Franklin, M., Bermudez, I., Cragg, S.J., 2013. Striatal dopamine transmission is reduced after chronic nicotine with a decrease in alpha6-nicotinic receptor control in nucleus accumbens. Eur. J. Neurosci. 38, 3036-3043.

Faraday, M.M., O'Donoghue, V.A., Grunberg, N.E., 1999a. Effects of nicotine and stress on startle amplitude and sensory gating depend on rat strain and sex. Pharmacol. Biochem. Behav. 62, 273-284.

Faraday, M.M., Scheufele, P.M., Rahman, M.A., Grunberg, N.E., 1999b. Effects of chronic nicotine administration on locomotion depend on rat sex and housing condition. Nicotine Tob. Res. 1, 143-151.

Faraday, M.M., Elliott, B.M., Grunberg, N.E., 2001. Adult vs. adolescent rats differ in biobehavioral responses to chronic nicotine administration. Pharmacol. Biochem. Behav. 70, 475-489.

Faraday, M.M., Elliott, B.M., Phillips, J.M., Grunberg, N.E., 2003a. Adolescent and adult male rats differ in sensitivity to nicotine's activity effects. Pharmacol. Biochem. Behav. 74, 917-931.

Faraday, M.M., O'Donoghue, V.A., Grunberg, N.E., 2003b. Effects of nicotine and stress on locomotion in Sprague-Dawley and Long-Evans male and female rats. Pharmacol. Biochem. Behav. 74, 325-333.

Faraday, M.M., Blakeman, K.H., Grunberg, N.E., 2005. Strain and sex alter effects of stress and nicotine on feeding, body weight, and HPA axis hormones. Pharmacol. Biochem. Behav. 80, 577-589.

Fung, Y.K., Lau, Y.S., 1986. Acute effect of nicotine on the striatal dopaminergic system in the rat. J. Pharm. Pharmacol. 38, 920-922.

Fung, Y.K., Lau, Y.S., 1988. Receptor mechanisms of nicotine-induced locomotor hyperactivity in chronic nicotine-treated rats. Eur. J. Pharmacol. 152, 263-271.

Fung, Y.K., Lau, Y.S., 1989. Effect of nicotine pretreatment on striatal dopaminergic system in rats. Pharmacol. Biochem. Behav. 32, 221-226.

Fung, Y.K., Lau, Y.S., 1991. Differential effects of chronic nicotine administration on dopaminergic receptor binding sites in rat nigrostriatal and mesolimbic regions. Gen. Pharmacol. 22, 117-119.

Fung, Y.K., Lau, Y.S., 1992. Chronic effects of nicotine on mesolimbic dopaminergic system in rats. Pharmacol. Biochem. Behav. 41, 57-63.

Fung, Y.K., Schmid, M.J., Anderson, T.M., Lau, Y.S., 1996. Effects of nicotine withdrawal on central dopaminergic systems. Pharmacol. Biochem. Behav. 53, 635-640.

George, O., Ghozland, S., Azar, M.R., Cottone, P., Zorrilla, E.P., Parsons, L.H., O'Dell, L.E., Richardson, H.N., Koob, G.F., 2007. CRF-CRF1 system activation mediates withdrawal-induced increases in nicotine self-administration in nicotine-dependent rats. Proc. Natl. Acad. Sci. USA 104, 17198-17203.

Henckens, M.J., Deussing, J.M., Chen, A., 2016. Region-specific roles of the corticotropinreleasing factor-urocortin system in stress. Nat. Rev. Neurosci. 17, 636-651.

Janhunen, S., Tuominen, R.K., Piepponen, T.P., Ahtee, L., 2005. Nicotine and epibatidine alter differently nomifensine-elevated dopamine output in the rat dorsal and ventra. striatum. Eur. J. Pharmacol. 511, 143-150.

Janhunen, S., Ahtee, L., 2007. Differential nicotinic regulation of the nigrostriatal and mesolimbic dopaminergic pathways: implications for drug development. Neurosci Biobehav. Rev. 31, 287-314.

Janssen, D., Kozicz, T., 2013. Is it really a matter of simple dualism? Corticotropin-releasing factor receptors in body and mental health. Front. Endocrinol. (Lausanne) $4,28$.

Kamdi, S.P., Nakhate, K.T., Dandekar, M.P., Kokare, D.M., Subhedar, N.K., 2009. Participation of corticotropin-releasing factor type 2 receptors in the acute, chronic and withdrawal actions of nicotine associated with feeding behavior in rats. Appetite 53, 354-362.

Kenny, P.J., Markou, A., 2001. Neurobiology of the nicotine withdrawal syndrome. Pharmacol. Biochem. Behav. 70, 531-549.

Liptak, N., Dochnal, R., Csabafi, K., Szakacs, J., Szabo, G., 2013. Obestatin prevents analgesic tolerance to morphine and reverses the effects of mild morphine withdrawal in mice. Regul. Pept. 186, 77-82.

Lovenberg, T.W., Liaw, C.W., Grigoriadis, D.E., Clevenger, W., Chalmers, D.T., De Souza, E.B., Oltersdorf, T., 1995. Cloning and characterization of a functionally distinct corticotropin-releasing factor receptor subtype from rat brain. Proc. Natl. Acad. Sci. USA $92,836-840$.

Marcinkiewcz, C.A., Prado, M.M., Isaac, S.K., Marshall, A., Rylkova, D., Bruijnzeel, A.W., 2009. Corticotropin-releasing factor within the central nucleus of the amygdala and the nucleus accumbens shell mediates the negative affective state of nicotine withdrawal in rats. Neuropsychopharmacology 34, 1743-1752.

Palotai, M., Bagosi, Z., Jaszberenyi, M., Csabafi, K., Dochnal, R., Manczinger, M., Telegdy, G., Szabo, G., 2013a. Ghrelin amplifies the nicotine-induced dopamine release in the rat striatum. Neurochem. Int. 63, 239-243.

Palotai, M., Bagosi, Z., Jaszberenyi, M., Csabafi, K., Dochnal, R., Manczinger, M., Telegdy, G., Szabo, G., 2013b. Ghrelin and nicotine stimulate equally the dopamine release in the rat amygdala. Neurochem. Res. 38, 1989-1995.

Pellegrino, L.J., Pellegrino, A.S., Cushman, A.J., 1979. A Stereotaxic Atlas of the Rat Brain. Plenum Press, New York.

Philpot, R.M., Engberg, M.E., Wecker, L., 2012. Effects of nicotine exposure on locomotor activity and pCREB levels in the ventral striatum of adolescent rats. Behav. Brain Res. 230, 62-68.

Portugal, G.S., Wilkinson, D.S., Turner, J.R., Blendy, J.A., Gould, T.J., 2012. Developmental effects of acute, chronic, and withdrawal from chronic nicotine on fear conditioning. Neurobiol. Learn. Mem. 97, 482-494.

Sarnyai, Z., Shaham, Y., Heinrichs, S.C., 2001. The role of corticotropin-releasing factor in drug addiction. Pharmacol. Rev. 53, 209-243.

Sengupta, P., 2013. The laboratory rat: relating its age with human's. Int. J. Prev. Med. 4, 624-630.

Szakacs, J., Csabafi, K., Liptak, N., Szabo, G., 2015. The effect of obestatin on anxiety-like behaviour in mice. Behav. Brain Res. 293, 41-45.

Vale, W., Spiess, J., Rivier, C., Rivier, J., 1981. Characterization of a 41-residue ovine hypothalamic peptide that stimulates secretion of corticotropin and beta-endorphin. Science 213, 1394-1397.

Van Pett, K., Viau, V., Bittencourt, J.C., Chan, R.K., Li, H.Y., Arias, C., Prins, G.S., Perrin, M., Vale, W., Sawchenko, P.E., 2000. Distribution of mRNAs encoding CRF receptors in brain and pituitary of rat and mouse. J. Comp. Neurol. 428, 191-212. 